\title{
Development of Metamaterial Inspired Nonuniform Circular Array Superstate Antenna using Characteristic Mode Analysis
}

K Durga Bhavani

Koneru Lakshmaiah Education Foundation

BTP Madhav ( $\sim$ btpmadhav@kluniversity.in )

Koneru Lakshmaiah Education Foundation https://orcid.org/0000-0002-6893-6978

MC Rao

Andhra Loyola College

Sudipta Das

IMPS College of Engineering and Technology

\section{Research Article}

Keywords: Characteristic Mode Analysis (CMA), Metasurface, Eigen Mode, WLAN

Posted Date: July 19th, 2021

DOl: https://doi.org/10.21203/rs.3.rs-638466/v1

License: (c) (i) This work is licensed under a Creative Commons Attribution 4.0 International License. Read Full License 


\title{
Development of Metamaterial Inspired Nonuniform Circular Array Superstate Antenna using Characteristic Mode Analysis
}

\author{
${ }^{1}$ K Durga Bhavani, ${ }^{1}$ B T P Madhav, ${ }^{2}$ M C Rao, ${ }^{3}$ Sudipta Das \\ ${ }^{1}$ Antennas and Liquid Crystals Research Center, Department of ECE, \\ Koneru Lakshmaiah Education Foundation, AP, India \\ ${ }^{2}$ Department of Physics, Andhra Loyola College, Vijayawada, AP, India \\ ${ }^{3}$ Department of ECE, IMPS College of Engineering and Technology, India
}

\begin{abstract}
In this work using characteristic mode analysis, a multi-layered nonuniform metasurface structured antenna has been optimized. The driven patch of square structure and the parasitic patch elements of circular radiating cross slotted metastructure are used in proposed model. The modal significance characteristic angles and surface currents are analysed based on characteristic mode to optimise the nonuniform structures. Antenna resonating between 5.5-6.1 GHz, covering WLAN applications with average gain of $7.9 \mathrm{~dB}$ and efficiency greater than $90 \%$. Transient mode, terminal mode and eigen mode-based analysis are performed on the proposed design and comparative analysis has been presented in this work. The prototype model fabrication and real time measurement analysis with simulation results matching is presented for application validation.
\end{abstract}

Keywords: Characteristic Mode Analysis (CMA), Metasurface, Eigen Mode, WLAN

\section{Introduction}

Now a days, the demand of novel wide band antennas is attracting more and more attention in the researchers towards wireless services such as WiMAX, Wi-Fi and WLAN. The world has to put its efforts for the development of wireless 5G system with integration of advanced communication modules [1]. So, the researchers have to endorse a new design approach for the fifth-generation wireless systems, which must fulfil the needs like higher data rates, reliability and good connectivity [2-3]. On the other hand, the design challenges need to be addressed and more focus should be on compatibility with environment. The major challenge in the design of working of communication systems will depend on the efficiency of the antenna system. The antenna needs to be reliable, adoptable and should have high gain bandwidth with good impedance matching. The microstrip antenna technology is more suitable and preferable to cater these needs with design simplicity and ease in impedance matching. Compared to other conventional antennas, the microstrip patch antennas are very popular due to light weight, easy of fabrication, less cost and also provide the wide band characteristics.

One of the promising techniques to achieve the wideband characteristics is, in the antenna structure loading a metasurface-layer which leads to increase the bandwidth and also reduce the size of the antenna [4-5]. Normally the natural materials exhibit positive permittivity $\epsilon[r]$, permeability $\mu[\mathrm{r}]$, and refractive index but metamaterials exhibit negative properties [6]. The metamaterial-based patch antenna for the improvement of bandwidth has been studied by Wu [7]. Metasurface is considered as a kind of two-dimensional metamaterial structure which contains a layer of electrically small scatters arranged in order by using certain rules [8]. Painam designed a circular microstrip patch antenna loaded with a metamaterial and size of the antenna is reduced to $74 \%$ compared to other conventional microstrip antennas [9]. A non-uniform metasurface layer is formed by adjusting the cells of the antenna to improve an overall radiation performance [10-13]. The unit cell size in a non-uniform 
metasurface layer is gradually increased from centre to outwards and achieved the wide bandwidth of $33.1 \%$ by Feng [14]. The wideband filtering of antenna is achieved by adjusting the size of unit cells on two sides of Y-axis [15]. In [16], the column unit cells size is adjusted on X-axis to achieve wideband characteristics of an antenna. Due to the lack of sufficient theoretical basics, the arrangement of unit cells in non-uniform metasurface layer to achieve the wideband characteristics is a tedious and time-consuming task.

Considering the defects and difficulties in the above-mentioned design methods, there in a need of more physical insights into the antenna design by the engineers. The characteristic mode analysis (CMA) is a most popular and efficient method which is proposed by Garbacz [16] and after modified by Harrington and Mautz [17-18] to optimize the antenna performance characteristics. The characteristic mode analysis (CMA) furnishes an in-depth physical insight into the antenna design aspect and its radiating properties. In recent years, using characteristic mode analysis different types of antennas are designed for various commercial and military communication applications, such as ultra-wideband antennas [ 20,21] and metasurface antennas [23-25]. In [26], a novel miniaturized metasurface unit cell is proposed and using this miniaturized unit cell, a $4 \times 4$ array antenna structure is composed. The design is analysed using theory of characteristic modes and realized circular polarization. In [27], $4 \times 4$ non-uniform array antenna is designed with H-shape patch array elements. The current distributions of metasurface and radiating properties are analyzed and obtained wide impedance bandwidth of $38.8 \%$. In [28], to realize the dual-band operation, a non-uniform $3 \times 3$ array antenna is designed using square shape patch elements.

In this work, a new multi-layered design is proposed and also optimized the metamaterial inspired $3 \times 3$ non-uniform array antenna using characteristic mode analysis (CMA). The antenna modelling and the simulation performance characteristics are realized on commercial electromagnetic tool HFSS and presented in the subsequent sections.

\section{Antenna Design}

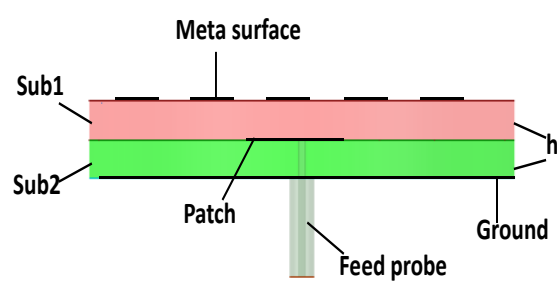

(a)

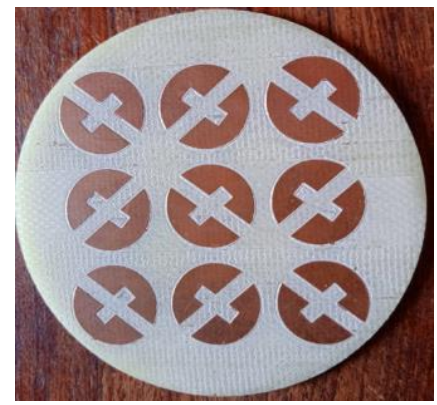

(c)

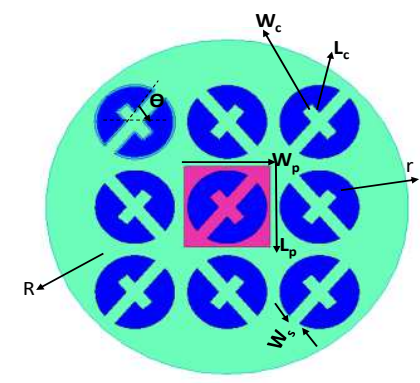

(b)

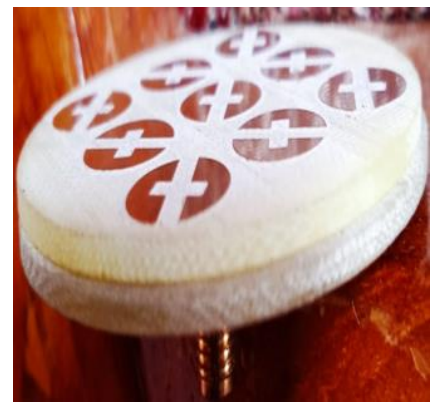

(d) 


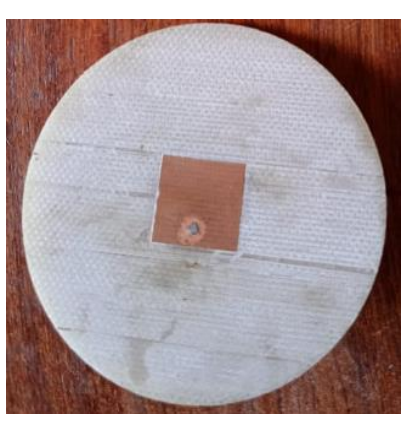

(e)

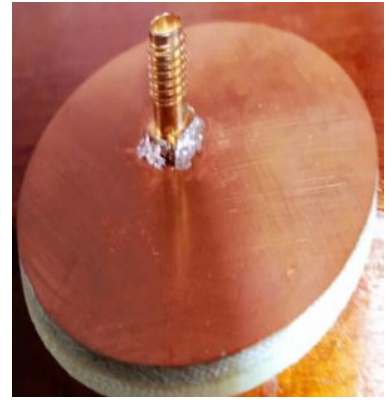

(f)

Figure 1. Nonuniform multilayered array antenna, (a) Side view of designed model, (b) Top view of simulated model, (c) Top view of prototyped model, (d) Side view of prototyped model, (e) Prototyped driven patch layer, (f) Antenna bottom view

The side and top view of proposed metamaterial inspired non-uniform array antenna design is presented in Figure 1. The designed antenna contains a non-uniform metasurface, patch antenna on two substrates named as sub1 and sub2. Both the substrates of circular shape are designed with the height of ' $h$ ' and radius of ' $R$ '. The substrate material used in the design is PDMS material having a loss tangent of 0.013 and relative permittivity of 2.7 and the conducting material used in the antenna design is copper. The ground plane also having the same radius as ' $R$ ' and covers the sub2 bottom part. The rectangular patch is printed on the sub 2 with a length of 'Lp' and width of ' $W p$ '. To achieve $50 \Omega$ impedance matching, a coaxial feeding technique is used and proper feeding location has been enhanced. According to the top view of antenna geometry shown, a non-uniform metasurface is designed with an array of $3 \times 3$ unit cells. Each unit cell covers an area of UL $\times$ UW and contains a circular radiating element of radius ' $r$ '. To improve the coupling effect between non-uniform metasurface layer and radiating antenna, the circular copper element is cut symmetrically into two parts by a slot width of 'Ws' and other cut of having length 'Lc' and width of 'Wc'. The angle ' $\Theta$ ' is defined as a rotation angle, which is the angle made between $\mathrm{x}$-axis and centre of the slot. The unit cells placed at the centre and all four corners are having counter clockwise direction of rotation angle and remaining unit cells are having opposite direction of rotation angle. The proposed antenna dimensions are given in Table 1.

\begin{tabular}{|l|l|}
\hline Description of the Parameter & $\begin{array}{l}\text { Value in } \\
\text { mm }\end{array}$ \\
\hline Radius of the Substrates, $\mathrm{R}$ & 27.5 \\
\hline Thickness of the Substrate, $\mathrm{h}$ & 2 \\
\hline Rectangular Patch Length, $\mathrm{L}$ & 13.27 \\
\hline Rectangular Patch width, W & 13 \\
\hline Radius of the circle, $\mathrm{r}$ & 6 \\
\hline Slot width, $\mathrm{W}_{\mathrm{s}}$ & 2 \\
\hline Cut Length, $\mathbf{L}_{\mathbf{c}}$ & 2 \\
\hline Width of the Cut, $\mathbf{W}_{\mathbf{c}}$ & 2 \\
\hline Rotation Angle, $\Theta$ & $40 \mathrm{deg}$ \\
\hline Width of unit cell, $\mathbf{U}_{\mathbf{w}}$ & 14 \\
\hline Length of unit cell, $\mathbf{U}_{\mathbf{L}}$ & 14 \\
\hline
\end{tabular}

Table 1: The nonuniform array antenna dimensions.

The Figure 2(a) represents modal, terminal, and transient analysis characteristics of the designed antenna array. It has been noticed that the transient mode analysis is contributing lesser bandwidth in comparison with modal and terminal analysis and the impedance bandwidth of 52\% only attained for the transient analysis, whereas for other two, an impedance bandwidth of $105 \%$ has been obtained. 


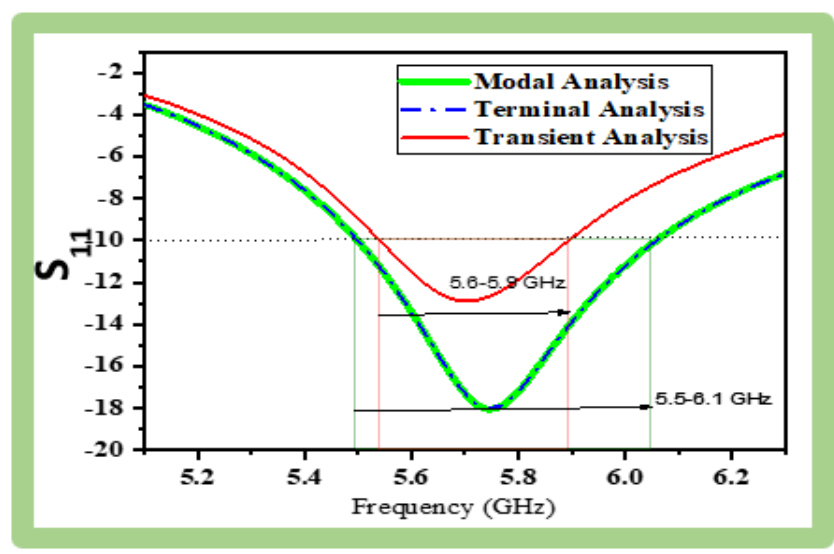

Figure 2. $\mathrm{S}_{11}$ for Modal, Terminal, and Transient Analysis

The Eigen mode analysis with respect to five modes of mode1, mode2, mode 3, mode 4 and mode 5 has been presented in Figure 3. This is giving a clear evidence regarding the resonant frequencies for each mode as per the operating frequency is concerned.

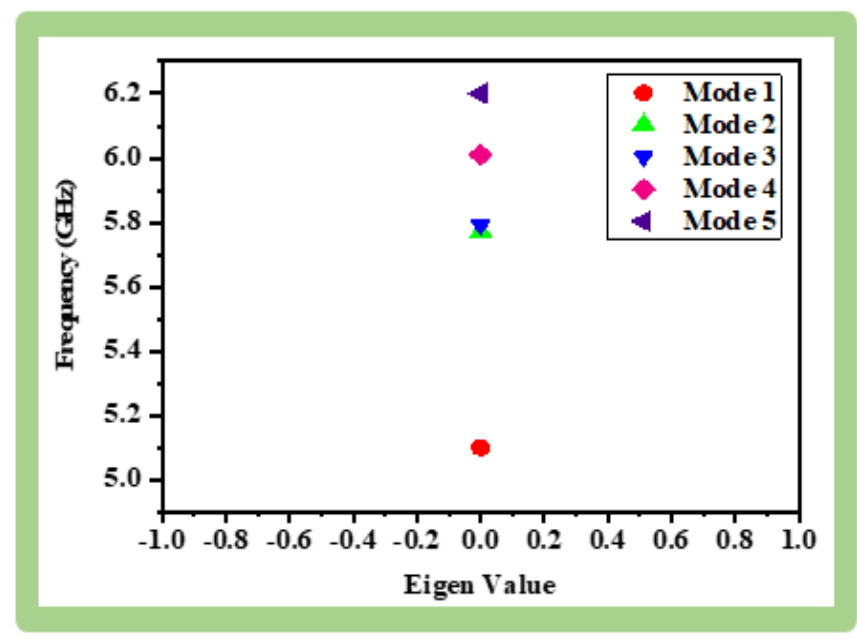

Figure 3. Eigen Mode analysis

\section{Unit Cell Design}

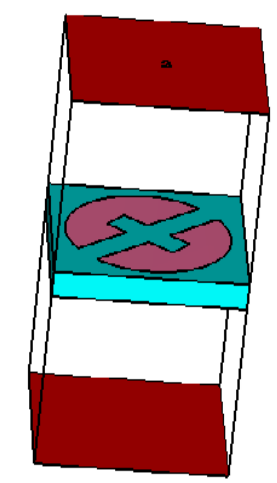

(a)

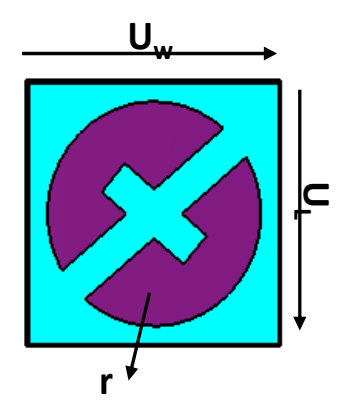

(b)

Figure 4. Unit Cell (a) with port assignment (b) Cross sectional view. 
The proposed array antenna unit cell structure has been presented in Figure 4. The unit cell with port assignment and the cross-sectional view with respect to dimensional characteristics are presented in Fig 4(a) and 4(b). The Fig-5\&6 represents the corresponding unit cell analysis parameters with respect to permittivity and permeability. The functional representation of these two parameters at resonating band with negative values can be observed from the obtained results. The metamaterial behaviour of the proposed design with negative characteristics giving strong motivation for the applicability of the given structure in the desired band.

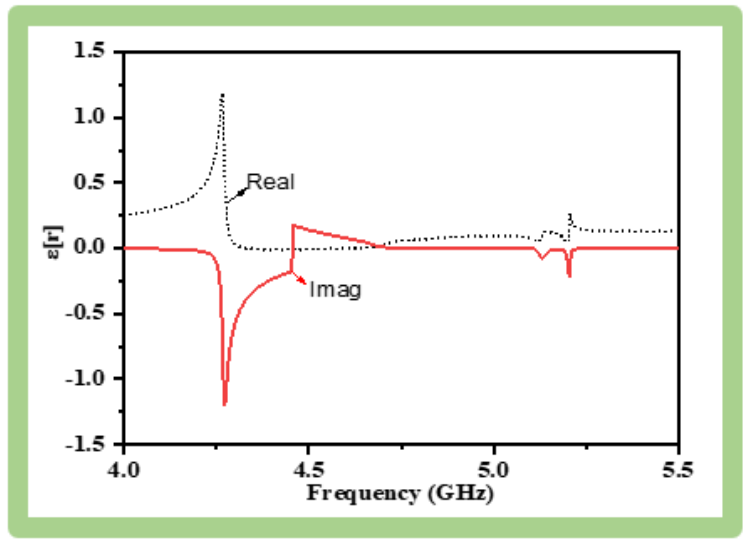

Figure 5. Frequency versus Permittivity plot

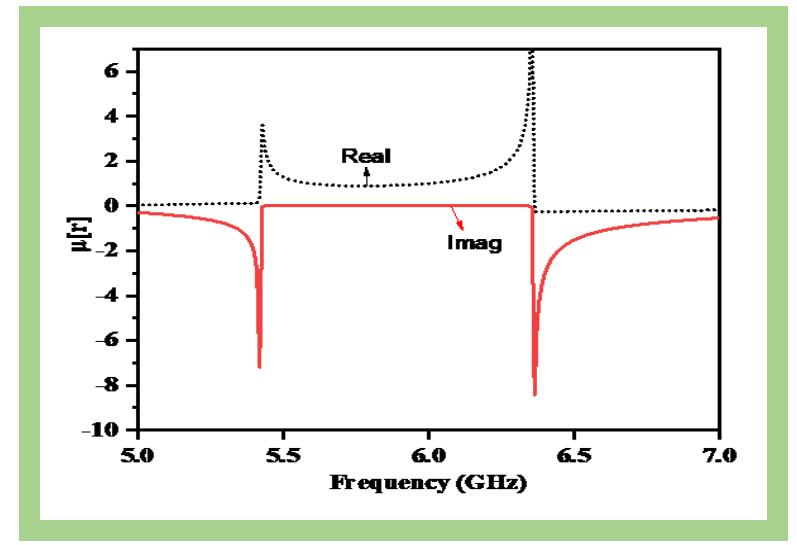

Figure 6. Frequency versus Permeability plot

\section{Characteristic Mode Analysis}

The Analysis of characteristic mode became a popular method to design the microstrip patch antenna which provides more physical insight into antenna resonance and radiation analysis. The characteristic modes are current modes which are associated with an eigen values that can be calculated numerically for arbitrarily shaped perfect electric conducting bodies (PEC). The theory of characteristic modes is depending only on shape and size of a conducting object and independent of any kind of excitation to achieve good performance of an antenna design. The CMA provides an inevitable approach for an antenna design, which is more efficient than cut-and-try methods or time-consuming optimizations [29]. The design of antenna can be performed in two steps using characteristic. In Step1, the size and shape of conducting elements are optimized. In Step 2, based on the current distributions provided by CMA, a suitable feeding configuration is chosen to excite desired characteristic modes. If the size of element is changed then the resonant frequency and radiating properties also will change. The derivations of characteristic modes and its various applications in antenna design are presented in [30]. 
The characteristic currents are derived by using eigen value equation,

$$
X\left[\vec{J}_{n}\right]=\lambda_{n} R\left[\vec{J}_{n}\right]
$$

Where, $\lambda_{n}$ represents the Eigen Values, $\vec{J}_{n}$ are nothing but the Eigen Currents or Eigen functions, $\mathrm{n}$ is the mode order and R and X are the Real and imaginary parts of impedance matrix is [31],

$$
\mathrm{Z}=\mathrm{R}+\mathrm{JX} \quad---
$$

The eigenvalue is a one of the utmost important parameters, because its magnitude is providing the valuable information about the resonant frequency and radiation information of the characteristic mode [32-33]. Consider a mode is resonating, the eigen value $\left(\lambda_{n}\right)$ associated with a mode is zero i.e. $\left|\lambda_{n}=0\right|$, it is stated that the mode radiates more efficiently when the magnitude of the eigen value is smaller.

when $\lambda_{n}=0$, the mode is externally resonant.

$\lambda_{n}>0$, the mode is inductive, means the energy is stored in a magnetic field.

$\lambda_{n}<0$, the mode is capacitive, means the energy is stored in an electric field.

The second important parameter in characteristic mode analysis is characteristic angle, it is an angle represents the phase lag between the electric field and surface current on a conductor object [34-35]. Mathematically, it is represented as,

$$
\alpha_{n}=180-\tan ^{-1} \lambda_{n}
$$

when $\alpha_{n}=180 \mathrm{deg}$, the mode is externally resonant.

$90 \mathrm{deg}<\alpha \mathrm{n}<180 \mathrm{deg}$, the mode is inductive

$180 \mathrm{deg}<\alpha \mathrm{n}<180 \mathrm{deg}$, the mode is capacitive.

Modal significance is the parameter used in CMA to find the resonant frequency and radiating bands of a specified mode. It is represented as,

$$
\mathrm{MS}=\frac{1}{\left|1+J \lambda_{n}\right|} \quad---
$$

In characteristic mode analysis a mode can be considered resonant when $\lambda_{n}=0, \mathrm{MS}=1$ and $\alpha_{n}=180$.

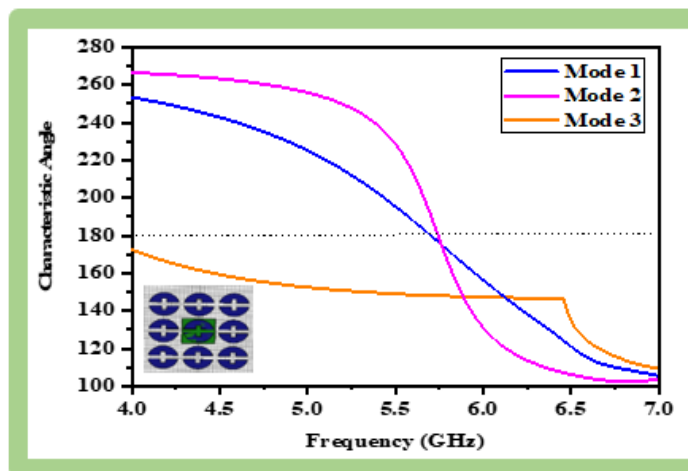

(a)

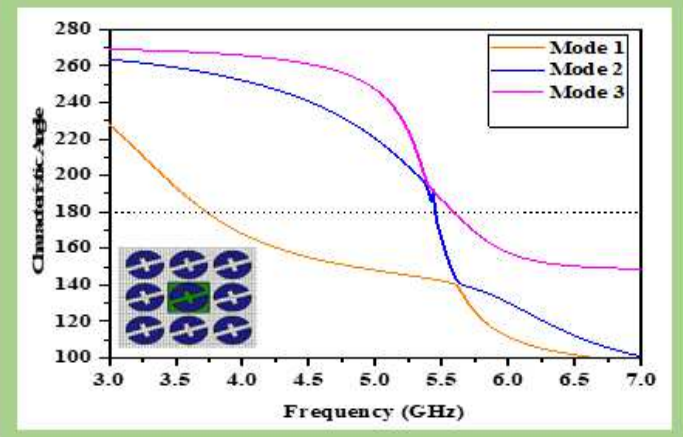

(b) 


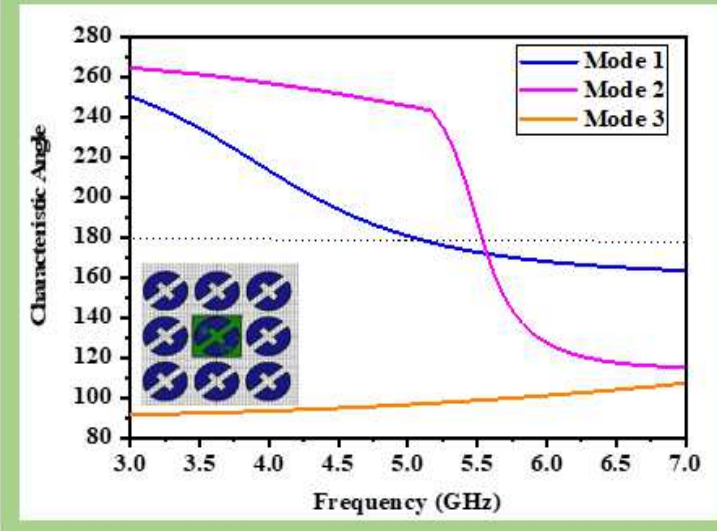

(c)

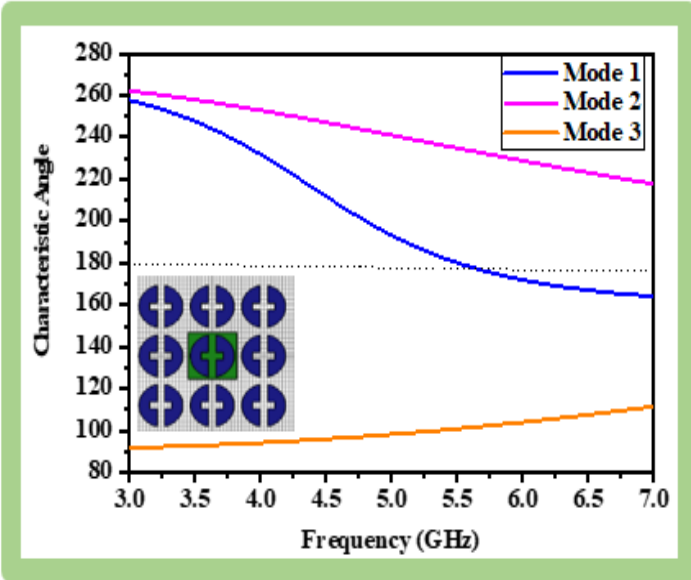

(e)

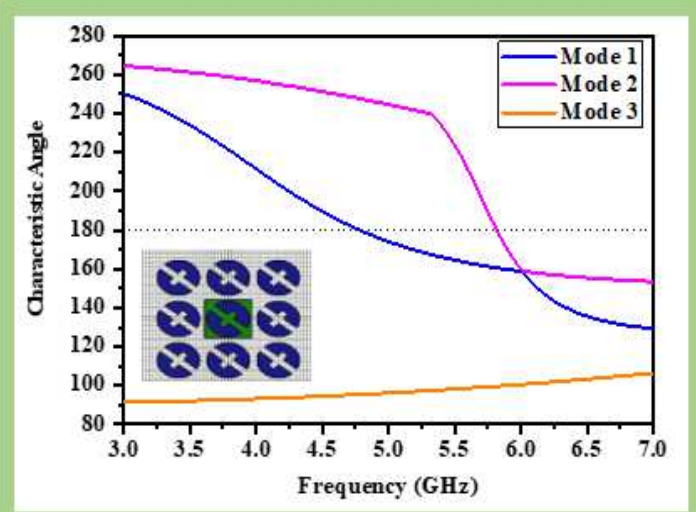

(g)

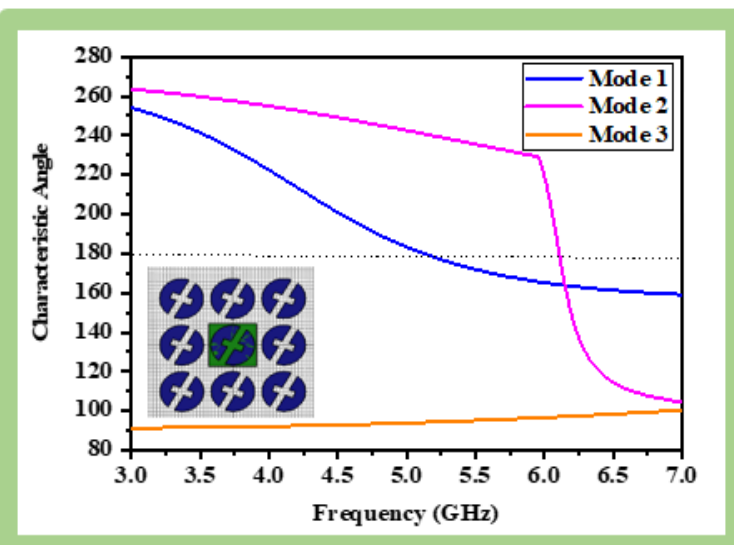

(d)

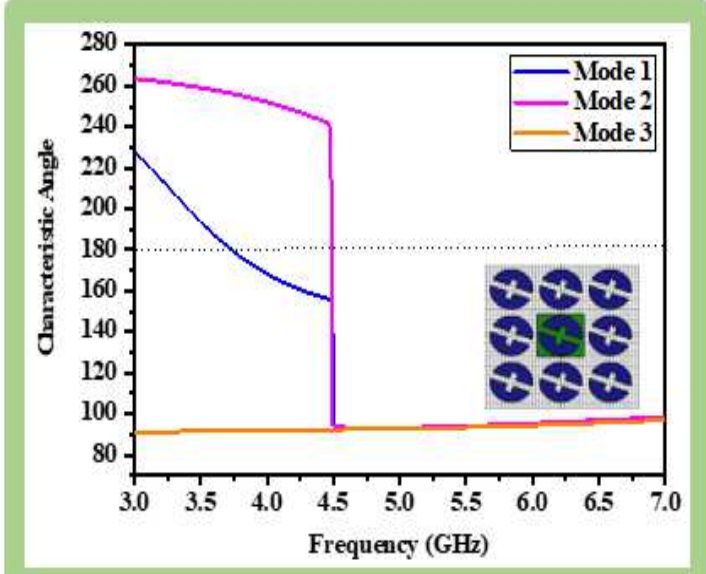

(f)

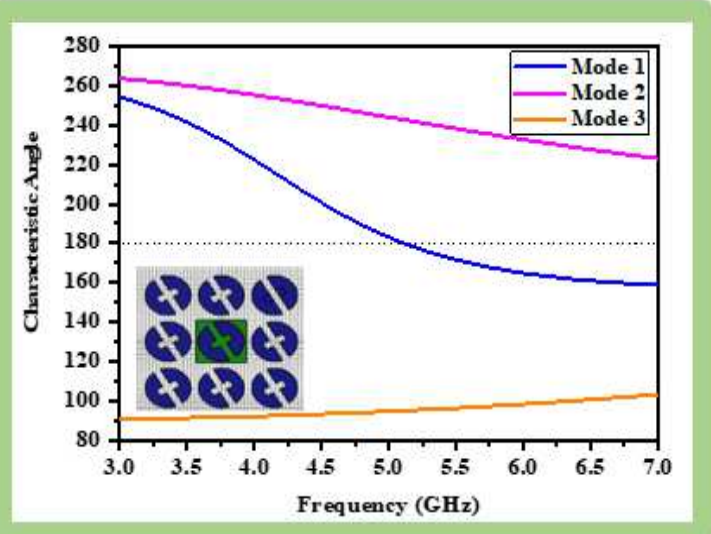

(h)

Figure 7. Characteristic Angle plot of proposed antenna (a) $\Theta=0^{\circ}$ (b) $\Theta=20^{\circ}$ (b) $\Theta=20^{0}$ (c) $\Theta=40^{\circ}$ (d) $\Theta=60^{\circ}$ (e) $\Theta=90^{\circ}$ (f) $\Theta=-20^{\circ}$ (g) $\Theta=-40^{\circ}$ (h) $\Theta=-60^{\circ}$

The frequency vs characteristic angle plots are presented in Fig 7. The rotation angle of the circular slots are varied from 0 deg to $90 \mathrm{deg}$ and $-20 \mathrm{deg}$ to $-60 \mathrm{deg}$ and analyzed the change in characteristic angle and presented the resonant frequency for the particular mode in Table 2. In mode 1 for rotation 
angle of $0 \mathrm{deg}$, the resonant frequency is varied between 3.7 to $5.6 \mathrm{GHz}$. In mode 2, the resonant frequency varied between 4.4 to $6.1 \mathrm{GHz}$ and at $90 \mathrm{deg}$ and $-60 \mathrm{deg}$ there is no resonance from the antenna. In mode 3 for only rotation angle of $20 \mathrm{deg}$, antenna resonating at $3.8 \mathrm{GHz}$ and for other angles, there is no resonance from the antenna.

\begin{tabular}{|l|l|l|l|}
\hline \multicolumn{4}{|c|}{ Characteristic Angles } \\
\hline Angle & Mode1 & Mode 2 & Mode 3 \\
\hline$\Theta=0^{0}$ & 5.6 & 5.7 & - \\
\hline$\Theta=20^{0}$ & 3.7 & 5.4 & 3.8 \\
\hline$\Theta=40^{0}$ & 5.0 & 5.5 & - \\
\hline$\Theta=60^{0}$ & 5.0 & 6.1 & - \\
\hline$\Theta=90^{0}$ & 5.49 & - & - \\
\hline$\Theta=-20^{0}$ & 3.7 & 4.48 & - \\
\hline$\Theta=-40^{0}$ & 4.7 & 5.8 & - \\
\hline$\Theta=-60^{0}$ & 5.09 & - & - \\
\hline
\end{tabular}

Table2. Mode Resonating Frequencies with respect to Characteristic Angle

The model significance analysis for the proposed antenna structure with reference to frequency of operation is indicated in Fig 8. Mode 1, Mode 2 and Mode 3 are analyzed with resonant frequency and presented the same in this section.

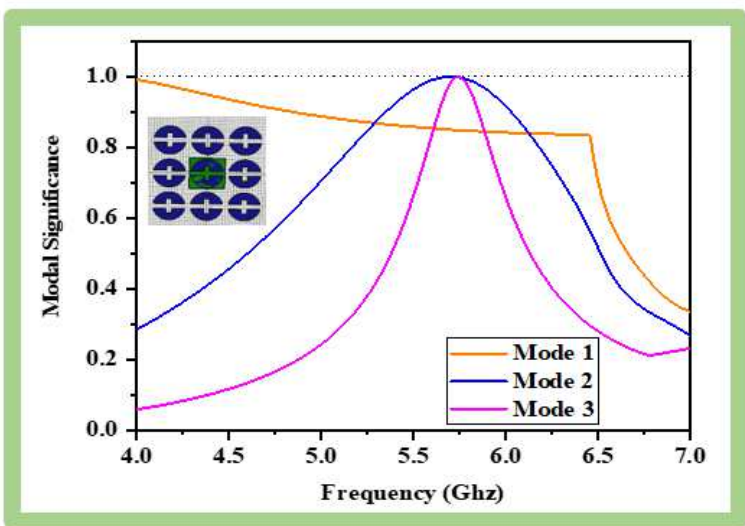

(a)

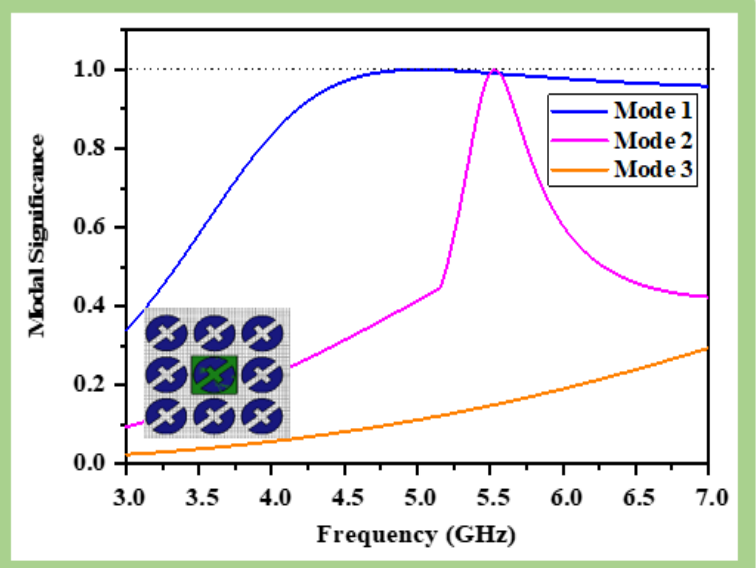

(c).

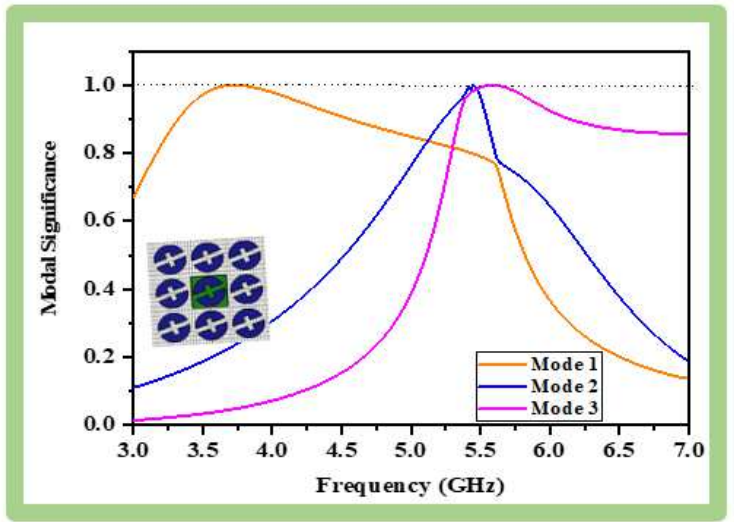

(b)

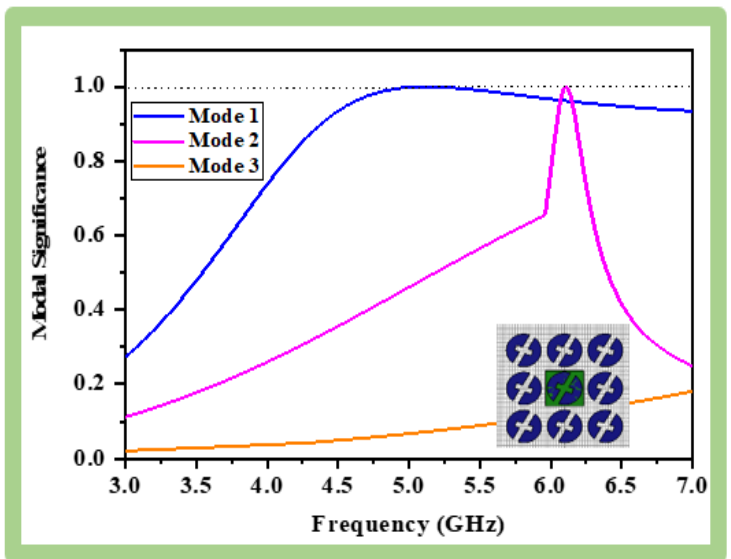

(d) 


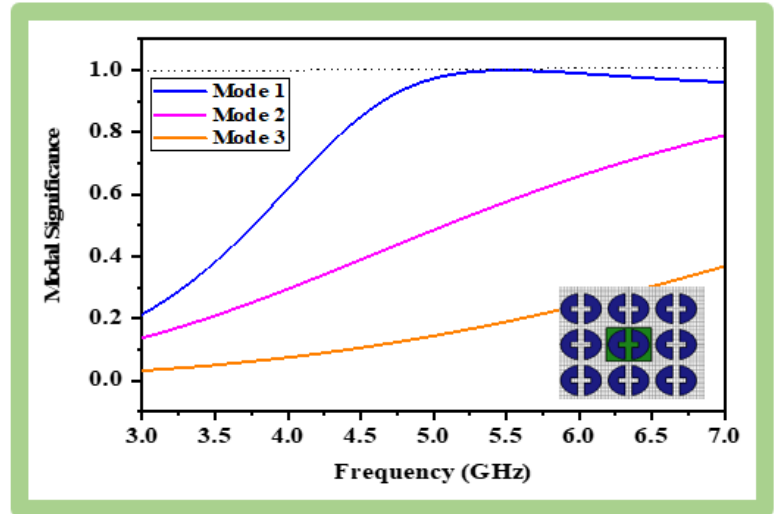

(e)

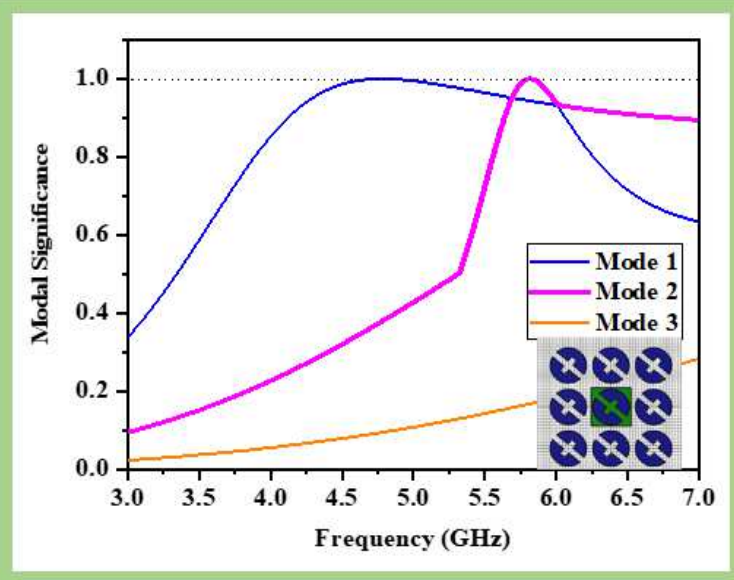

(g)

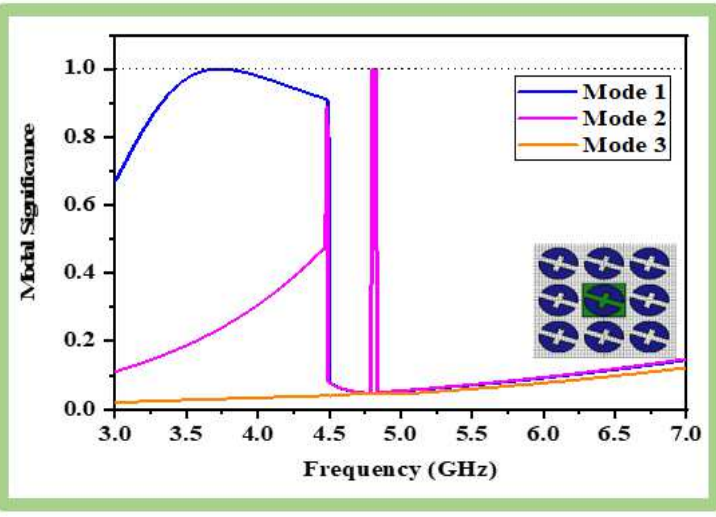

(f)

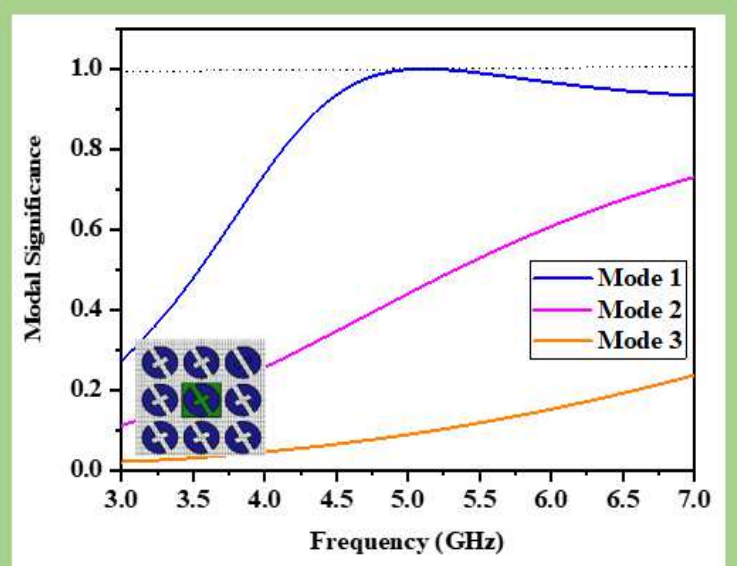

(h)

Figure 8. Modal significance plot of proposed antenna (a) $\Theta=0^{0}$ (b) $\Theta=20^{\circ}$ (b) $\Theta=20^{\circ}$ (c) $\Theta=40^{0}$ (d) $\Theta=60^{\circ}$ (e) $\Theta=90^{\circ}(\mathrm{f}) \Theta=-20^{\circ}(\mathrm{g}) \Theta=-40^{\circ}(\mathrm{h}) \Theta=-60^{\circ}$

The change the rotation angle of the slots in the radiating element are varied from 0 degree to 90 degree and from -20 degree to -60 degree. For 20 degree there are three resonant frequencies for three modes at $3.7,5.4$ and $3.8 \mathrm{GHz}$, respectively.

For 90 degree and -60 degree, there is only single resonant frequency at 5.4 and $5 \mathrm{GHz}$, respectively. For $0,20,40,60,-20$ and -40 degree, both mode 1 and mode 2 providing different resonant frequency of operation from Table 3.

\begin{tabular}{|l|l|l|l|}
\hline \multicolumn{4}{|c|}{ Modal Significance (MS=1) } \\
\hline Angle & Mode1 & Mode 2 & Mode 3 \\
\hline$\Theta=0^{0}$ & 5.6 & 5.7 & - \\
\hline$\Theta=20^{0}$ & 3.7 & 5.4 & 3.8 \\
\hline$\Theta=40^{0}$ & 5.0 & 5.5 & - \\
\hline$\Theta=60^{0}$ & 5.0 & 6.1 & - \\
\hline$\Theta=90^{0}$ & 5.49 & - & - \\
\hline$\Theta=-20^{0}$ & 3.7 & 4.48 & - \\
\hline$\Theta=-40^{0}$ & 4.7 & 5.8 & - \\
\hline$\Theta=-60^{0}$ & 5.09 & - & - \\
\hline
\end{tabular}

Table 3: Mode Resonating Frequencies with respect to Modal Significance 


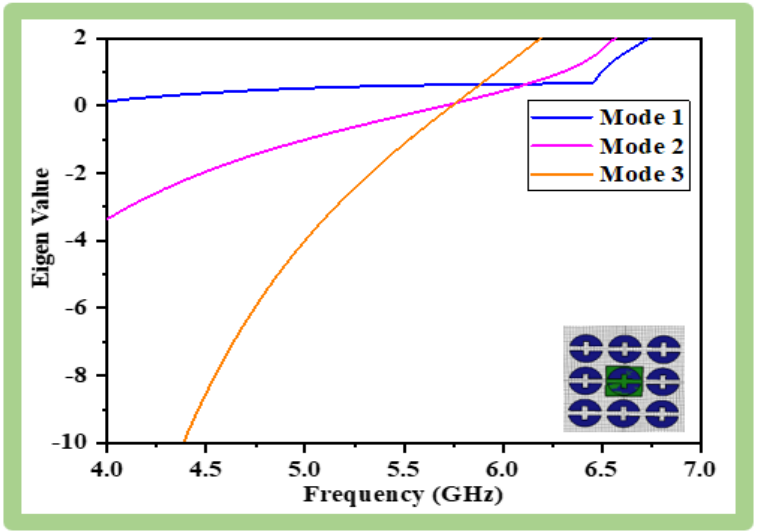

(a)

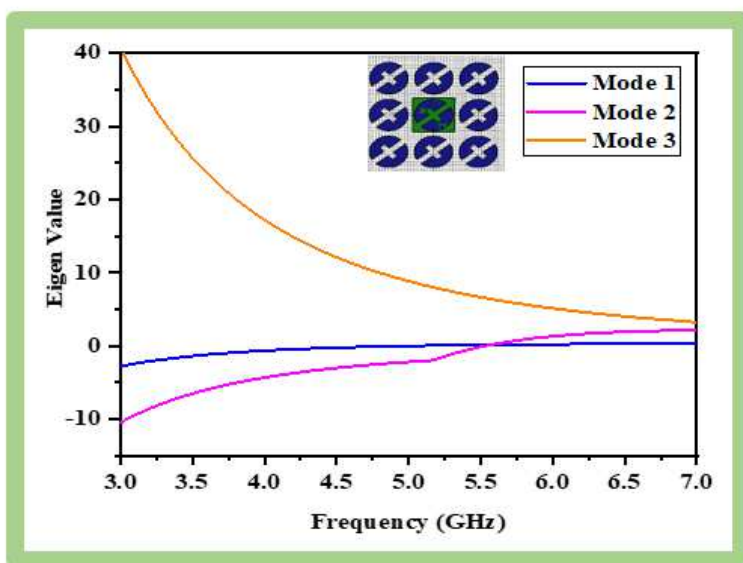

(c)

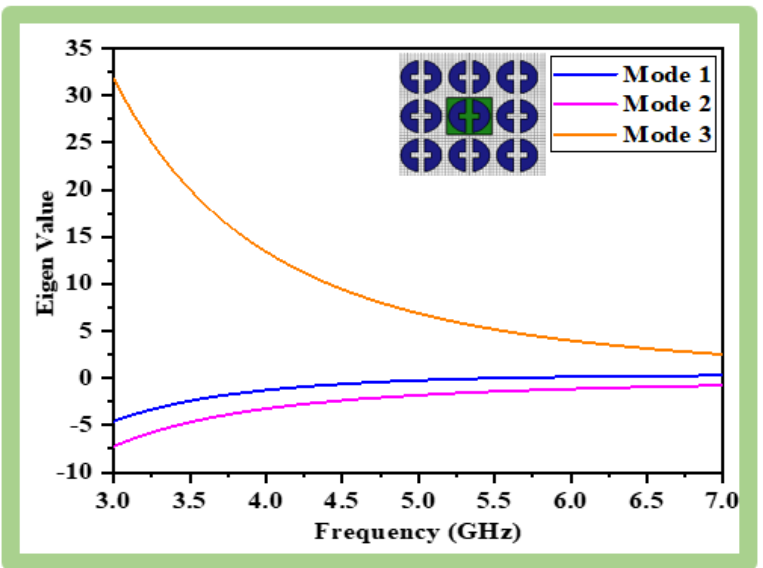

(e)

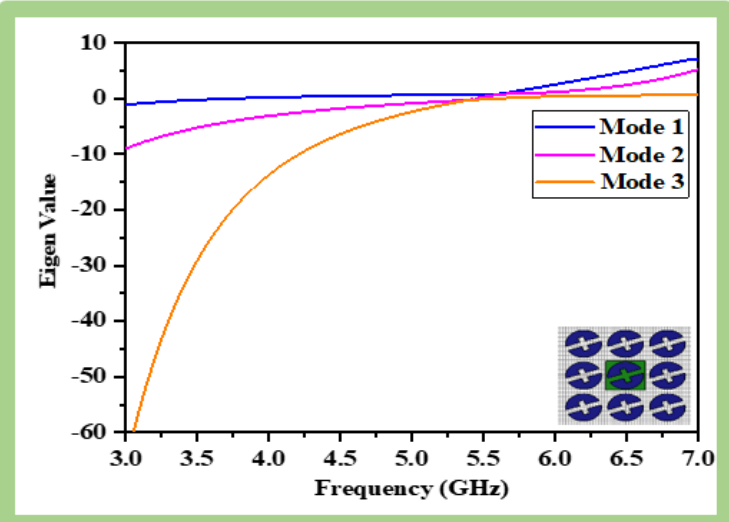

(b)

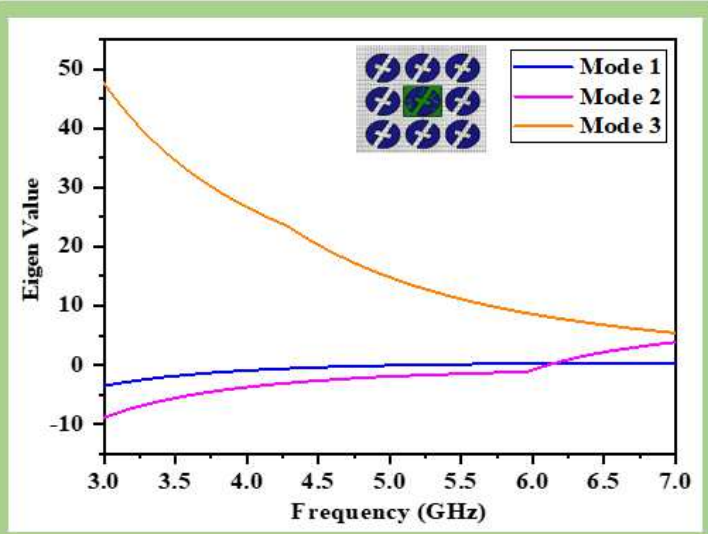

(d)

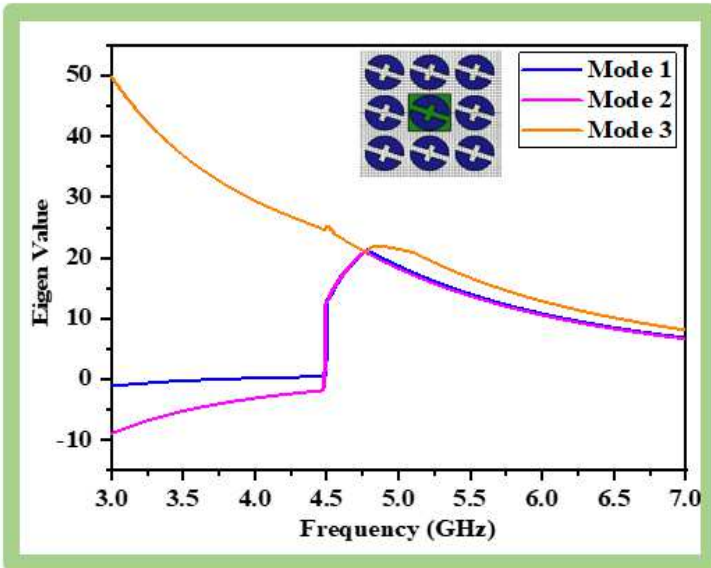

(f) 


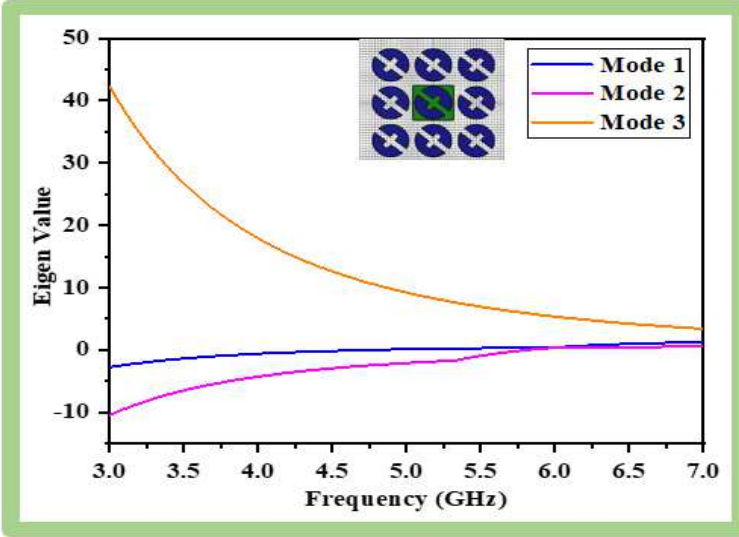

(g)

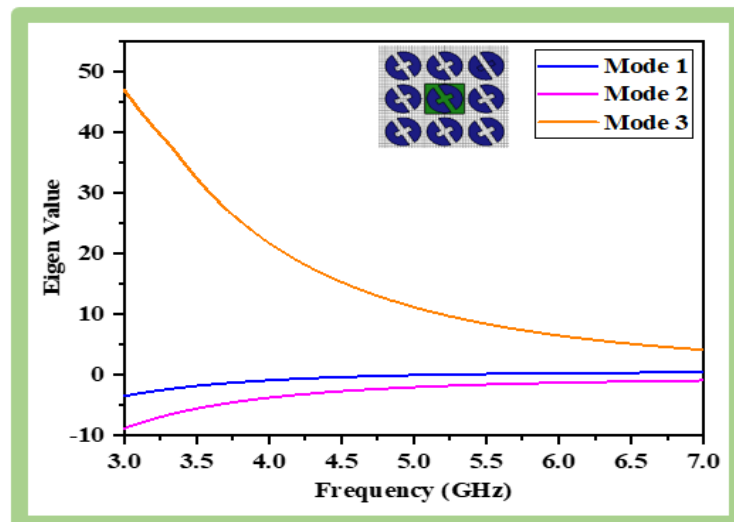

(h)

Figure 9. Frequency Vs Eigen Value plot of proposed antenna (a) $\Theta=0^{\circ}$ (b) $\Theta=20^{\circ}$ (b) $\Theta=20^{\circ}$ (c) $\Theta=40^{\circ}$ (d) $\Theta$ $=60^{\circ}$ (e) $\Theta=90^{\circ}$ (f) $\Theta=-20^{\circ}$ (g) $\Theta=-40^{\circ}(\mathrm{h}) \Theta=-60^{\circ}$

The Eigen value analysis with respect to resonant frequency is presented in Fig 9 for different angles of rotation. Table 4. Except for $90 \mathrm{deg}$ and $-60 \mathrm{deg}$, single resonant mode and for $20 \mathrm{deg}$ triple resonant modes are observed. Similar kind of observation is attained for eigen value from Table 4 and modal significance analysis from Table 3.

\begin{tabular}{|l|l|l|l|}
\hline \multicolumn{4}{|c|}{ Eigen Value $\left(\lambda_{n}=0\right)$} \\
\hline Angle & Mode1 & Mode 2 & Mode 3 \\
\hline$\Theta=0^{0}$ & 5.6 & 5.7 & - \\
\hline$\Theta=20^{0}$ & 3.7 & 5.4 & 3.8 \\
\hline$\Theta=40^{0}$ & 5.0 & 5.5 & - \\
\hline$\Theta=60^{0}$ & 5.0 & 6.1 & - \\
\hline$\Theta=90^{0}$ & 5.49 & - & - \\
\hline$\Theta=-20^{0}$ & 3.7 & 4.48 & - \\
\hline$\Theta=-40^{0}$ & 4.7 & 5.8 & - \\
\hline$\Theta=-60^{0}$ & 5.09 & - & - \\
\hline
\end{tabular}

Table 4. Mode Resonating Frequencies with respect to Eigen Value

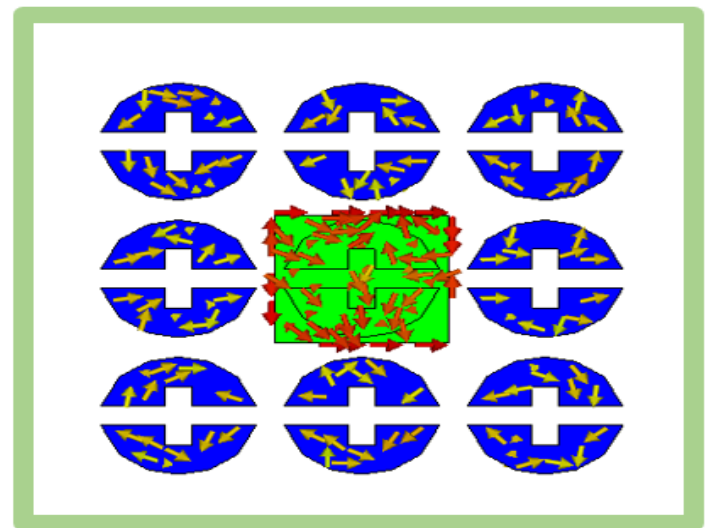

(a)

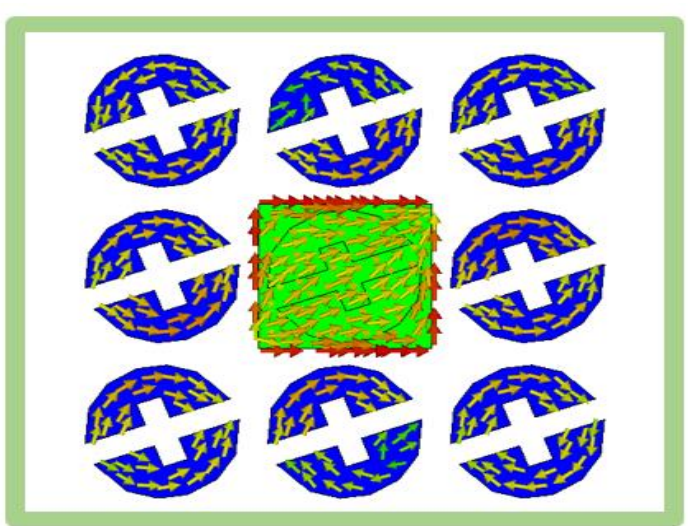

(b) 


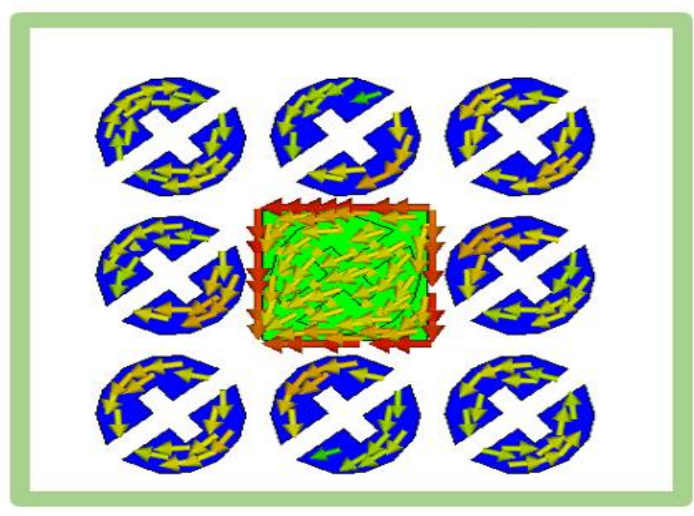

(c)

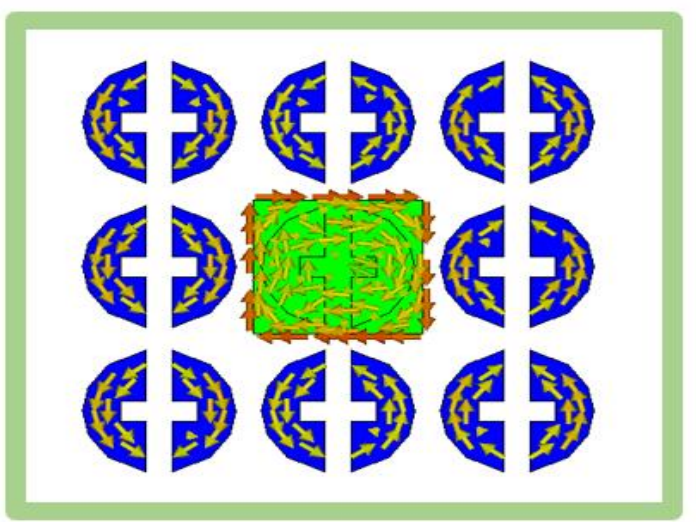

(e)

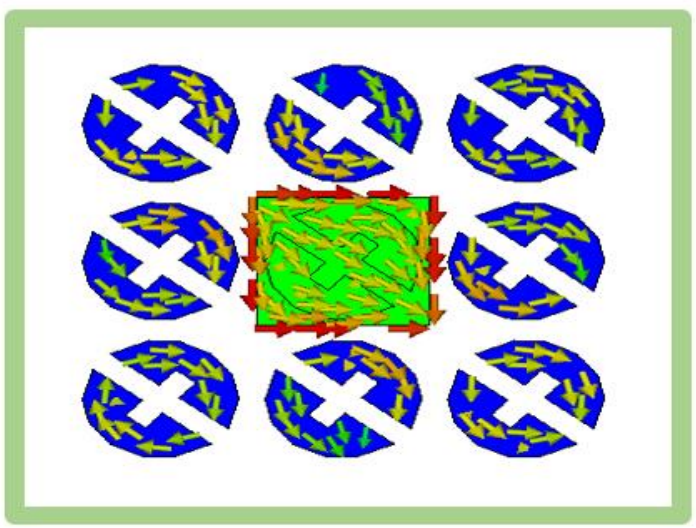

(g)

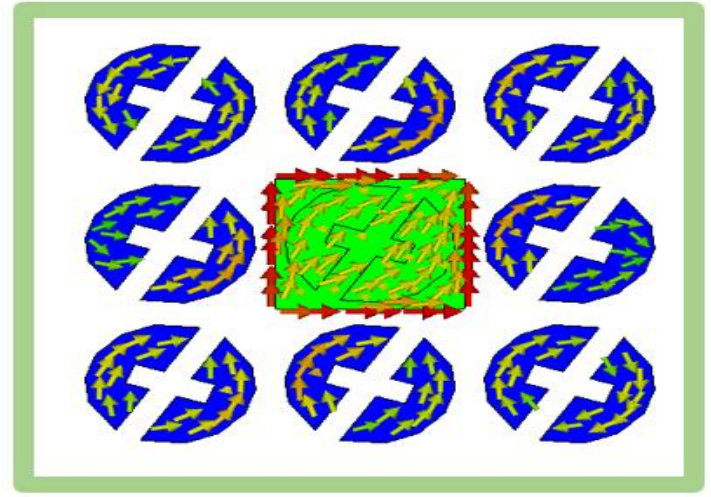

(d)

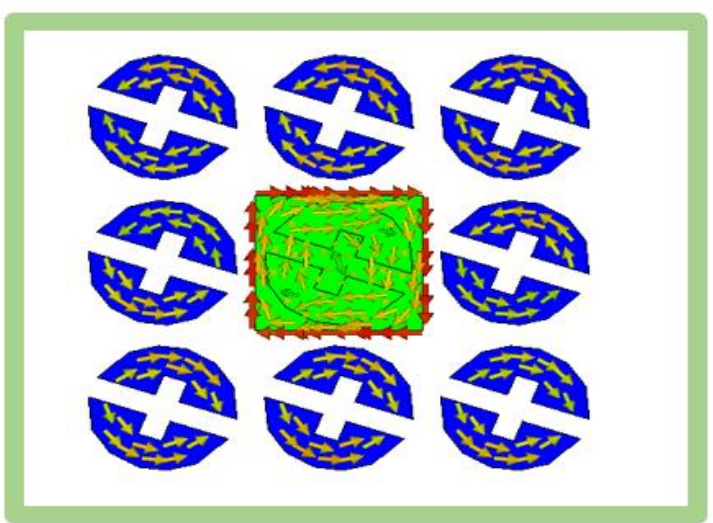

(f)

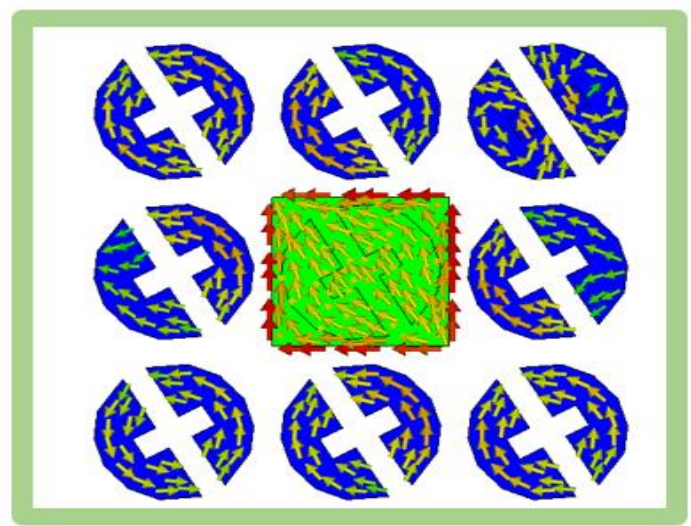

(h)

Figure 10. Surface Current distributions of proposed antenna (a) $\Theta=0^{\circ}$ (b) $\Theta=20^{\circ}$ (b) $\Theta=20^{\circ}$ (c) $\Theta=40^{\circ}$ (d) $\Theta$ $=60^{\circ}(\mathrm{e}) \Theta=90^{\circ}(\mathrm{f}) \Theta=-20^{\circ}(\mathrm{g}) \Theta=-40^{\circ}(\mathrm{h}) \Theta=-60^{\circ}$

The surface current distribution analysis of the designed antenna for different rotation angles are presented in Fig 10. The circular orientation of current elements direction in all the cases giving evidence of polarization diversity and in each unit cell the strength of current is consistent. The direction of current in Mode 1 is along $\mathrm{y}$-axis and in Mode 2 is along x-axis. 


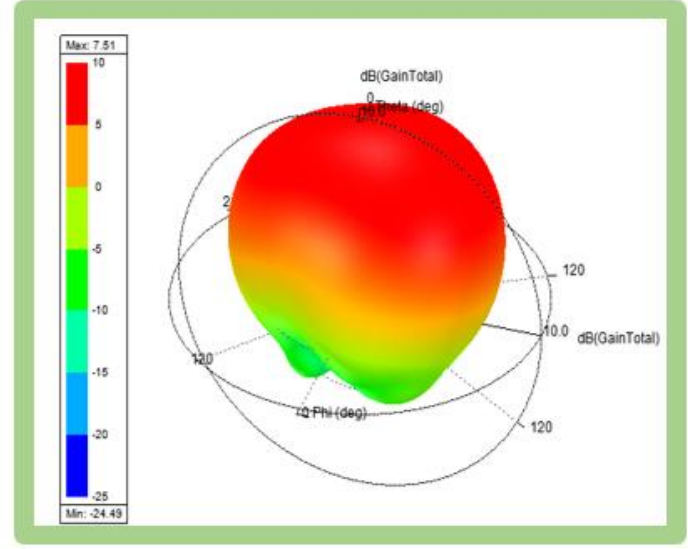

(a)

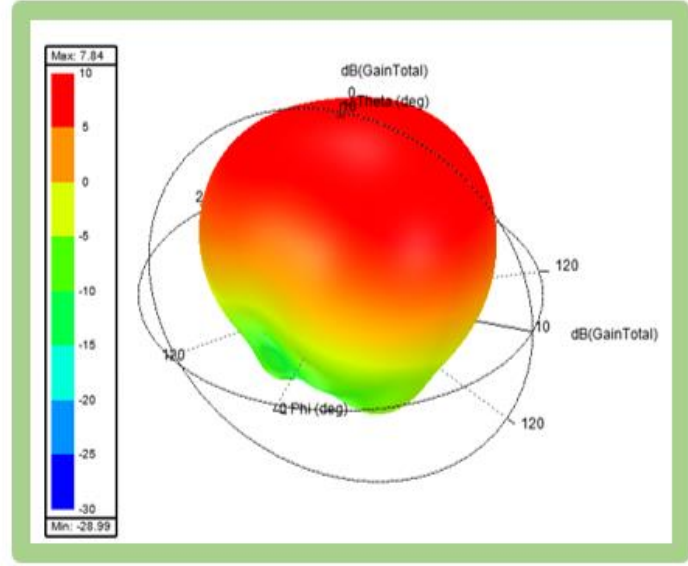

(c)

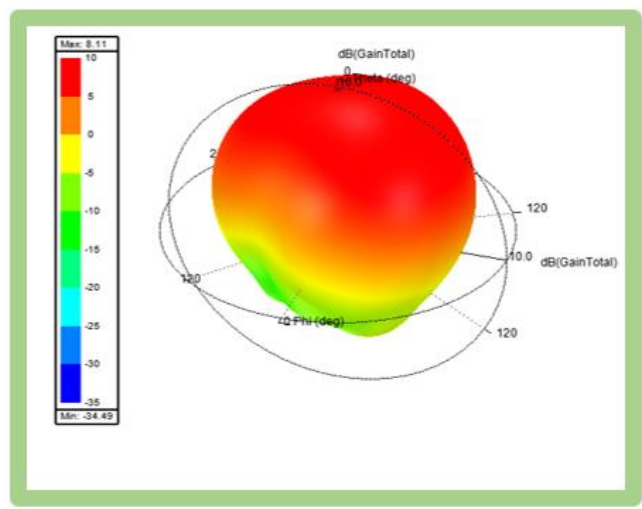

(e)

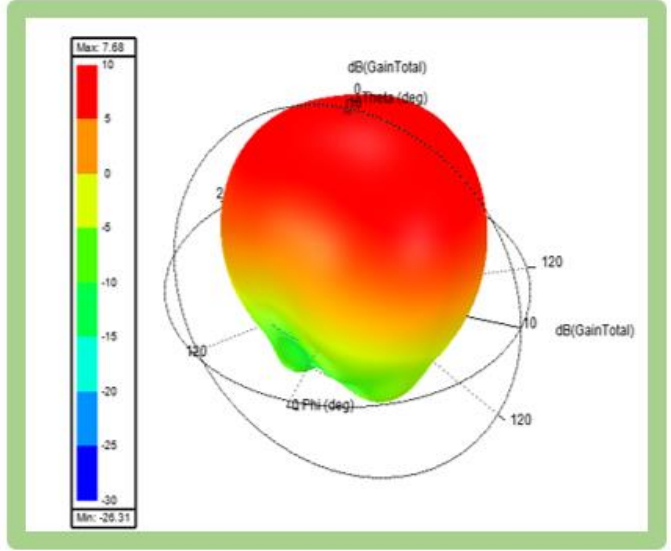

(b)

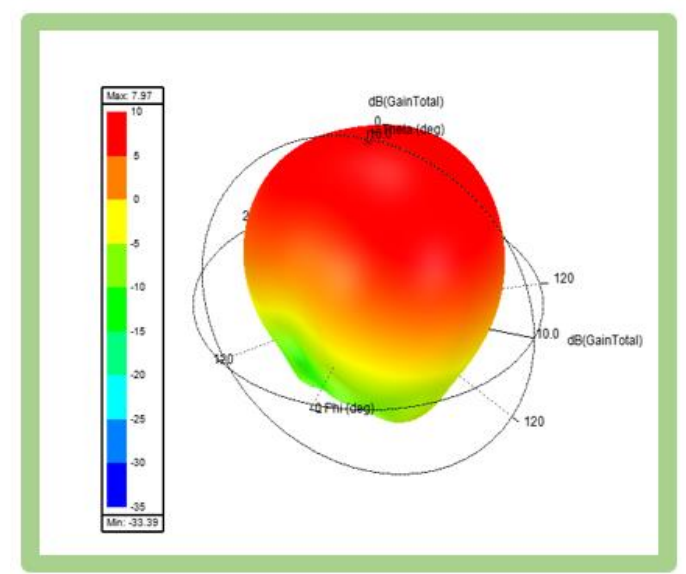

(d)

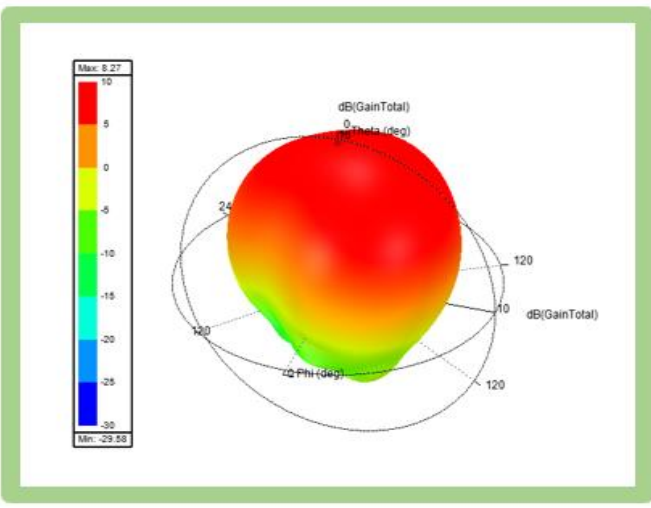

(f)

Figure 11. Gain plot (a) $5.4 \mathrm{GHz}$ (b) $5.5 \mathrm{GHz}$ (c) $5.6 \mathrm{GHz}$ (d) $5.7 \mathrm{GHz}$ (e) $5.8 \mathrm{GHz}$ (f) $6.1 \mathrm{GHz}$

The three-dimensional gain plots of the current antenna is presented in Fig 11. The gain plots at different resonant frequencies of various modes are analyzed and presented. At $5.4 \mathrm{GHz}$ of Mode $2(\Theta$ $\left.=20^{\circ}\right)$, a maximum gain of $7.5 \mathrm{~dB}$ is attained. At $5.5 \mathrm{GHz}$ of Mode $2\left(\Theta=40^{\circ}\right)$, a maximum gain of 7.6 $\mathrm{dB}$ is attained. At $5.6 \mathrm{GHz}$ of Mode $1\left(\Theta=0^{0}\right)$, a maximum gain of $7.8 \mathrm{~dB}$ is attained. At $5.7 \mathrm{GHz}$ of Mode $2\left(\Theta=0^{0}\right)$, a maximum gain of $7.9 \mathrm{~dB}$ is attained. At $5.8 \mathrm{GHz}$ of Mode $2\left(\Theta=-40^{\circ}\right)$, a maximum gain of $8.1 \mathrm{~dB}$ is attained. At $6.1 \mathrm{GHz}$ of Mode $2\left(\Theta=60^{\circ}\right)$, a maximum gain of $8.2 \mathrm{~dB}$ is attained. 
Fig 11 providing the simulated and measured reflection coefficient of the antenna with perfect matching between them. The gain and efficiency plot in Fig 12 providing average gain of $7.8 \mathrm{~dB}$ and efficiency of more than $90 \%$. The comparative analytical study of the proposed model with literature is provided in Table 5. The impedance bandwidth, gain and efficiency are showing better performance characteristics when compared with existing antenna models.

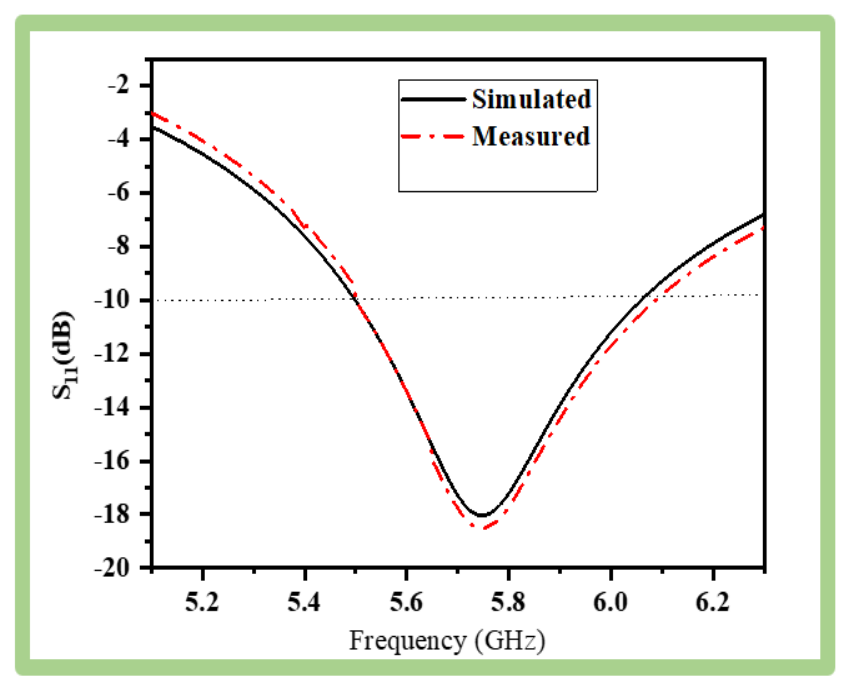

Figure 11. Measured and simulated reflection coefficient

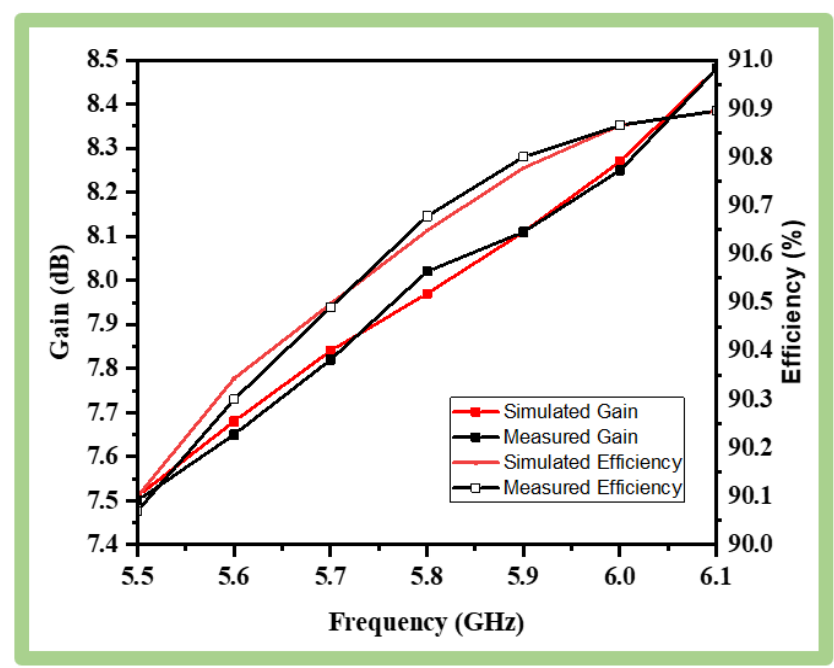

Figure 12. Frequency Vs Gain and Frequency Vs Efficiency Plot

\begin{tabular}{|l|l|l|l|l|l|l|l|}
\hline S. No & $\begin{array}{l}\text { Referenc } \\
\mathrm{e}\end{array}$ & $\begin{array}{l}\text { No. of unit } \\
\text { cells }\end{array}$ & $\begin{array}{l}\text { Physical } \\
\text { Dimensions } \\
\left(\mathrm{L} \times \mathrm{W} \mathrm{mm} \mathrm{mm}^{2}\right.\end{array}$ & Bandwidth $(\mathrm{GHz})$ & $\begin{array}{l}\text { Peak gain } \\
(\mathrm{dBi})\end{array}$ & $\begin{array}{l}\text { Impedance } \\
\text { Band width } \\
(\%)\end{array}$ & $\begin{array}{l}\text { Average } \\
\text { Efficiency } \\
(\%)\end{array}$ \\
\hline 1 & {$[5]$} & $11 \times 11$ & $132 \times 132$ & $5.71-5.88$ & 13.7 & $10 \%$ & NR \\
\hline 2 & {$[14]$} & $8 \times 8$ & $55 \times 55$ & $4.56-6.37$ & 6.34 & $33.1 \%$ & NR \\
\hline 3 & {$[15]$} & $4 \times 4$ & $78 \times 78$ & $4.2-5.59$ & 8.2 & $30 \%$ & NR \\
\hline 4 & {$[32]$} & $7 \times 7$ & $80 \times 60$ & $3.27-4.66$ & 7.7 & $45 \%$ & NR \\
\hline 5 & {$[33]$} & $10 \times 10$ & $60 \times 60$ & $4.9-5.1$ & 11.6 & $11 \%$ & NR \\
\hline 6 & {$[34]$} & $3 \times 3$ & $27.5 \times 2$ & $5.07-5.94$ & 7.6 & $163 \%$ & $80 \%$ \\
\hline 7 & {$[35]$} & $2 \times 3$ & $20 \times 20$ & 10,15 & $8.24,9.26$ & $40 \%, 18 \%$ & $82 \%, 87 \%$ \\
\hline 8 & Proposed & $3 \times 3$ & $27.5 \times 2$ & $5.5-6.01$ & 8.1 & $105 \%$ & $>90 \%$ \\
\hline
\end{tabular}

Table 5. Comparison of proposed and other antenna designs (NR-not Reported, DB-Dual Band) 


\section{Conclusion}

A non-uniform slotted array with multilayer structured antenna is designed in this work for WLAN communication applications. Characteristic mode analysis has been examined to optimize the antenna performance characteristics as per the application specification. The slotted structure metamaterial characteristics are analyzed for the designed model with respect to negative permittivity and negative permeability at targeted operating band. Characteristic angle, modal significance parameters and eigen values are analyzed and presented with respect to resonant frequency in the current work. Peak gain of $8.1 \mathrm{~dB}$, impedance bandwidth of $105 \%$ and efficiency more than $90 \%$ is attained with good matching between simulation and measurement results.

\section{Acknowledgements}

Thanks to DST FIST- SR/FST/ET-II/2019/450 for providing research facilities

\section{References}

[1] S. Ohmori, Y. Yamao, and N. Nakajima, "The Future Generations of Mobile Communications Based on Broadband Access Technologies”, IEEE Communication Magazine vol. 38, no, 12, pp. 134-142, 2010.

[2] M. M. M. Ali, O. Haraz, and S. Alshebeili, "Design of Dual-Band Printed Slot Antenna with Utilizing a Band Rejection Element for the 5G Wireless Applications", IEEE International Symposium on Antennas Propagation, Fajardo, Puerto Rico, 26 June - 1 July, pp. 1865-1866, 2016.

[3] S. F. Jilani and A. Alomainy, "Millimetre-wave T-Shaped MIMO Antenna with Defected Ground Structures for 5G Cellular Networks", IET Microwaves Antennas \& Propagation, vol. 12, no, 5, pp. 672-677, 2018.

[4] Z. Wu, L. Li, Y. J. Li, and X. Chen, "Metasurface Superstrate Antenna with Wideband Circular Polarization for Satellite Communication Application," IEEE Antennas Wireless Propag. Lett., vol. 15, pp. 374377, Jun. 2015.

[5] G. P. Gao, C. Yang, B. Hu, S. F. Wang, and R. F. Zhang, "Design of a High-Gain and Low-Profile QuasiCassegrain Antenna Based on Metasurfaces," IEEE Antennas Wireless Propag. Lett., vol. 17, pp. 1435-1439, Aug. 2018.

[6] Tadesse AD, Acharya OP, Sahu S. "Application of metamaterials for performance enhancement of planar antennas: A review", International Journal of RF and Microwave Computer-Aided Engineering. 2020 May;30(5): e22154.

[7] W. Wu, B. Yuan, B. Guan, and T. Xiang, "A Bandwidth Enhancement for Metamaterial Microstrip Antenna", Microwave Optical Technology Letter vol. 59, no, 12, May, pp. 3076-3082, 2017.

[8] C. L. Holloway, E. F. Kuester, J. A. Gordon, J. O'Hara, J. Booth, and D. R. Smith, “An Overview of the Theory and Applications of Metasurfaces: The Two-Dimensional Equivalents of Metamaterials," IEEE Antennas Propag. Mag., vol. 54, no. 2, pp. 10-35, Apr. 2012.

[9] S. Painam and C. Bhuma, "Miniaturizing a Microstrip Antenna Using Metamaterials and Metasurfaces [Antenna Applications Corner]," in IEEE Antennas and Propagation Magazine, vol. 61, no. 1, pp. 91-135, Feb. 2019

[10] H. L. Zhu, Y. X. Cao, and G. Wei, "Study on Non-uniform Meta-surface for Antenna Design," in 2018 IEEE International Conference on Signal Processing, Communications and Computing (ICSPCC), Sep. 2018.

[11] S. Painam, and C. Bhuma, "Miniaturizing a Microstrip Antenna Using Metamaterials and Metasurfaces," IEEE Antennas Propag. Mag., vol. 61, no. 1, pp. 91-135, Feb. 2019. 
[12] M. Bosiljevac, Z. Sipus, M. Casaletti, F. Caminita, and S. Maci, "Designing Horn Antennas Based on Variable Metasurface Concept," in 2012 6th European Conference on Antennas and Propagation (EUCAP), pp. 1692-1695, Mar. 2012.

[13] Z. B. Wang, H. Wu, J. C. Chen, Z. H. Wu, and Y. J. Feng, “An Ultralow-profile Lens Antenna Based on Alldielectric Metasurfaces," in 2016 IEEE 5th Asia-Pacific Conference on Antennas and Propagation (APCAP), pp. 367-368, Jul. 2016.

[14] G. Feng, L. Chen, X. Xue and X. Shi, "Broadband Surface-Wave Antenna With a Novel Nonuniform Tapered Metasurface," in IEEE Antennas and Wireless Propagation Letters, vol. 16, pp. 2902-2905, 2017.

[15] Y. M. Pan, P. F. Hu, X. Y. Zhang, and S. Y. Zheng, "A low-profile high-gain and wideband filtering antenna with metasurface,” IEEE Trans. Antennas Propag., vol. 64, no. 5, pp. 2010-2016, May 2016.

[16] R. J. Garbacz and R. H. Turpin, "A generalized expansion for radiated and scattered fields," IEEE Transactions on Antennas and Propagation, vol. 19, no. 3, pp. 348-358, 1971

[17] R. F. Harrington and J. R. Mautz, "The Theory of Characteristic Modes for Conducting Bodies," IEEE Transactions on Antennas and Propagation, vol. 19, no. 5, pp. 622-628, 1971.

[18] R. F. Harrington, J. R. Mautz, and J. Y. Chang, "The Theory of Characteristic Modes for Dielectric and Magnetic Bodies,” IEEE Transactions on Antennas and Propagation, vol. 20, no. 2, pp. 194-198, 1972.

[19] Zhang, Q., Q. Zhang, and Y. Gao, "Design of a multi-mode UWB antenna using characteristic mode analysis," IEEE Transactions on Antennas and Propagation, Vol. 66, No. 7, 3712-3717, Jul. 2018.

[20] Zhang, Q. and Y. Gao, "Compact low-profile UWB antenna with characteristic mode analysis for UHF TV white space devices,” IET Microwaves, Antennas \& Propagation, Vol. 11, No. 11, 1629-1635, 2017

[21] Ma, R., T.-Y. Shih, R. Lian, and N. Behdad, "Design of bandwidth-enhanced, platform-mounted, electrically-small VHF antennas using the characteristic-mode theory," IEEE Antennas and Wireless Propagation Letters, Vol. 17, No. 12, 2384-2388, Dec. 2018

[22] Li, T. and Z. N. Chen, "Metasurface-based shared-aperture 5G S/K-band antenna using characteristic modes analysis," IEEE Transaction on Antennas and Propagation, Vol. 66, No. 12, 6742-6750, 2018.

[23] Santill'an-Haro, D., E. A. Daviu, D. S. Escuderos, and M. F. Bataller, "Analysis and design of a metamaterial lens antenna using the theory of characteristic modes," International Journal of Antennas and Propagation, Vol. 2018, Article ID 6329531, 8 pages, 2018.

[24] Li, T. and Z. N. Chen, "A dual-band metasurface antenna using characteristic mode analysis," IEEE Transactions on Antennas and Propagation, Vol. 66, No. 10, 5620-5624, Oct. 2018.

[25] Lin, F. H. and Z. N. Chen, "Truncated impedance-sheet model for low-profile broadband nonresonant-cell metasurface antennas using characteristic mode analysis," IEEE Transactions on Antennas and Propagation, Vol. 66, No. 10, 5043-5051, Oct. 2018.

[26] Y. Juan, W. C. Yang, and W. Q. Che, "Miniaturized low-profile circularly polarized metasurface antenna using capacitive loading,” IEEE Trans. Antennas Propag., vol. 67, no. 5, pp. 3527-3532, May 2019.

[27] C. Zhao, and C. F. Wang, "Characteristic mode design of wide band circularly polarized patch antenna consisting of H-shaped unit cells,” IEEE Access, vol. 6, pp. 25292-252299, Apr. 2018.

[28] T. Li, and Z. N. Chen, "A dual-band metasurface antenna using characteristic mode analysis," IEEE Trans. Antennas Propag., vol. 66, no. 10, pp. 5620-5624, Oct. 2018.

[29] Vogel, M., G. Gampala, D. Ludick, U. Jakobus, and C. J. Reddy, "Characteristic mode analysis: Putting physics back into simulation," IEEE Antennas and Propagation Magazine, Vol. 57, No. 2, 307-317, Apr. 2015. 
[30] R. F. Harrington and J. R. Mautz, "Computation of Characteristic Modes for Conducting Bodies", IEEE Transactions on Antennas Propagation vol. 19, no, 5, pp. 629-639, 1971

[31] Y. Chen and C. Wang, "Characteristic Modes Theory Applications in Antenna Engineering", Hoboken NJ, USA: John Wiley \& Sons, 2015

[32] Nasimuddin, X. Qing, and Z. N. Chen, "Metasurface-based low profile broadband circularly polarized antenna," Proceedings of TENCON 2017-2017 IEEE Region 10 Conference, Penang, 2017, pp.2378-2382.

[33] H. L. Zhu, S. W. Cheung, J. Guo, C. Ding, and T. I. Yuk, “Aperture Efficiency Improvement Using Metasurface," in 2016 10th European Conference on Antennas and Propagation (EuCAP), Apr. 2016.

[34] Gao G, Zhang RF, Geng WF, Meng HJ, Hu B. "Characteristic Mode Analysis of a Nonuniform Metasurface Antenna for Wearable Applications". IEEE Antennas and Wireless Propagation Letters. 2020 Jun 9;19(8):1355-9.

[35] Hamad, Ehab KI, and Ahmed Abdelaziz. "Metamaterial superstrate microstrip patch antenna for 5G wireless communication based on the theory of characteristic modes." Journal of Electrical Engineering 70.3 (2019): 187-197. 